Thareas serenus, Plötz (1587), =Entheus eumelus, Cram., 9 .

Pyprhopyge porus, Plötz (1595) = Mimoniades pityusa, Hew.

Colombia.

" parima, Plötz (1597)

Surinam.

Belongs to Yanguna. Not represented in the G. \& S. coll.

" leucoloma, Ersch. Very near P. sergius, Hopff., but (1599), Peru. with the white patch on the underside of the secondaries extending further inward.

XXV.-Function and Form with Reference to the Hand and Foot in Man and Apes. By Duncan C. L. Fitzwildiams, M.D., Ch.M., F.R.C.SS. Ed. \& Eng., Demonstrator of Anatomy, King's College, London; Casualty Officer, Hospital for Sick Children, Great Ormond Street.

\title{
[Plate V.]
}

Throvgh the kindness of Professor Cunningham I was enabled to carry out a systematic anatomical study of a gibbon (Hylobates agilis) in his possession. In this paper I wish to deal only with the description of the hands and feet of the animal, and incidentally to draw attention to the differences existing in the hands and feet of man.

The orang-utangs, chimpanzees, gorillas, and gibbons are the four great tribes which form the anthropoid family. The larger members of the family resemble man in stature and outward form more nearly than the gibbon, but on closer investigation the gibbon presents certain characteristics which have led many eminent anatomists to place this ape next to man in the scale of animal life. With the single exception of man, the gibbon can assume the erect posture more completely than any other animal.

\section{The Hand.}

The hand of the gibbon (Pl. V. fig. 1, A) is remarkable for the great length it possesses in comparison with its width. Measured from the crease in front of the wrist to the tip of the longest finger the length amounts to $15 \frac{1}{2} \mathrm{~cm}$., but the breadth of the widest part, just above the root of the little finger, does not exceed $3 \frac{1}{4} \mathrm{~cm}$. The length is due to the development both of the metacarpals and phalanges.

The thenar and hypothenar eminences are small ; indeed, so feeble is the development of the latter that it can scarcely 


$$
\equiv
$$


be said to exist. The thumb is short in comparison with the rest of the hand; it extends slightly beyond the level of the metacarpo-phalangeal joint of the second digit, but not as far as the web between the second and third. In man the thumb reaches to the level of the proximal interphalangeal articulation of the index, while the interphalangeal joint of the thumb is on a level with the metacarpo-phalangeal joint of the second digit.

The web of the gibbon's thumb is very small, not reaching halfway down the first metacarpal bone. This gives rise to an appearance as if the palm and the thumb sprang separately from the region of the wrist. In marked contrast to this, the webs of the fingers are much more extensive than those of man, and reach nearly halfway down the elongated proximal phalanges, thereby lengthening the palm at the expense of the fingers. This extensive webhing prevents separation of the fingers to any great extent. As in man, the third digit is the longest. The fingers are placed parallel to one another, but show slight ability to oppose the thumb.

'I'he positions of the deep creases of the skin are as follows:-

1. In front of the wrist there is a deep transverse crease due to the flexion of this joint.

2. From just below the midpoint of the wrist-crease another starts, and runs downwards and outwards into the deep cleft which intervenes between the thenar eminence and the rest of the palm. This crease and cleft are caused by the adduction of the thumb. In man the great development of the thumbmuscles has filled out the cleft and increased the web, while the upper limit of the crease curves outwards round the thenar eminence well below the creases of the wrist.

3. Starting from the same point as the preceding, a crease passes downwards and inwards to the inner margin of the palm, just above its centre. The causation of this line is not very evident, as the muscles of the hypothenar eminence are small. Of such a crease little or no trace is to be found in the human hand: but in the foot of the ape a very similar marking is found in front of the outer part of the heel, the part which corresponds to the hypothenar eminence of the hand (see Pl. V. tig. 1, B).

4. In common with the two preceding yet another crease starts and runs longitudinally down the palm to the root of the third digit.

5. Parallel and to the outer side of the last-mentioned crease is a shorter crease which ends at the cleft between the second and third digits. These creases result probably from the contraction of the contrahentes and palmar interosseous 
muscles, which causes the digits to converge on the central one. Both these creases are usually found in the hand of man, but are fainter, more irregular, and more obliquely placed. I believe that cheiromancy attributes great brainpower to the individual possessing one of these lines in a well-marked degree, an assumption highly complimentary to the ape.

6. About a third of the way down the palm is a crease passing transversely across.

7. Halfway down the palm a crease passes across in a curved manner with the concavity towards the wrist.

8. A curved crease, parallel to the last mentioned, is situated about two thirds of the way down the palm. These last two creases evidently correspond to the two deeply marked creases which run obliquely across the human pal:n. All three transverse creases are due to the folding of the palmar tissues during flexion of the fingers. T'he obliquity of the lines in the human hand results from the great amount of opposability which exists between the human thumb and the inner four digits. The extra line found in the palm of the ape is probably accounted for, partly by the increased length of the palm, and partly by the constantly flexed position of the hand.

9. Deep creases are present at the roots of the fingers on a level with the webs. These creases run transversely in the case of the second and third digits and obliquely in the case of the fourth and fifth. This same arrangement, though to a less marked degree, is present in the hand of man; the creases of the two outer fingers are transverse, while those of the two inner have an oblique tendency.

The long slender fingers of this ape (Pl. V. fig. 2) are remarkably flat on their palmar aspect. They all exhibit, to a greater or less degree, a longitudinal crease which runs down the centre of the palmar surface. This crease is best marked on the middle digit. It will be seen later that the finer skin-lines of the fingers converge on these central creases.

Owing to the proximal interphalangeal joint of the middle digit being marked in front by two widely separated transverse lines, this digit appears to possess four instead of three phalanges. The thenar eminence is marked by a series of oblique lines running downwards and inwards. On adducting the human thumb similar lines may appear.

The terminal phalanges are bulbous and projecting. The free part of the nail stands well away from the back of the phalanx; in man the nail lies quite close to the back of the ungual phalanx. As the nail of the thumb is the shortest, 
broadest, and least arched, it most closely resembles the human nail. As one approaches the little finger the nail of each digit becomes successively longer, narrower, more arched, and therefore more claw-like, in a manner analogous to that noted by Wiedersheim in the human hand. This is due to the greater and more varied use to which the nails of the outer digits are put; that of the little finger, being the least used, retains in a greater degree than the others its primitive claw-like character.

The fine lines on the palmar skin are much coarser than those on the human hand, and in many cases pass interruptedly across the deep creases of the palm.

The coarseness of the finer lines is probably a response to the requirements of function: the animal uses its hands as hooks by which to suspend the weight of the body from the branches, and the friction produced by the finer lines gives firmness to the grip. If the skin of the palm were devoid of lines and perfectly smooth a firm grip, with no slipping, would be difficult to obtain. The delicacy of the lines of the human hand is due to the fact that the hand is no longer an organ merely of grasp, but used for many varied and highly specialized movements.

In the gibbon the lines are arranged in a definite manner and one well calculated to obviate the risk of the hand slipping from a branch. In the lower part of the palm the lines show a general tendency to converge towards the central digit. In the fingers the lines are arranged in a chevron-like manner, converging from the margins downwards towards the longitudinal crease which runs along the centre of each digit. This arrangement is best seen on the proximal and middle phalanges of the third and fourth digits, where the weight of the body chiefly rests. The lines of the proximal and middle phalanges of the second and fifth digits, like the lines of the palm, have a tendency to converge towards the central digit. This tendency survives in the human hand only on those parts which are used solely for grip and not for the execution of any of the finer movements. It is well seen on the palm near to, and on the proximal phalanges of, the index and little fingers, whilst elsewhere the lines run in an irregular manner, forming whorls and triangles which differ in individual hands. This wonderful difference in the patterns met with on the thumb is used by the police in the identification of criminals.

Oblique lines are found to be more efficient mechanical agents for the prevention of slipping than transverse. For 
this reason the driving-wheels of all heavy traction-engines are provided with sloping or chevron lines.

Professor Goodsir [I] many years ago pointed out that the hand of man was the only perfect hand, and that while the ape's hand was fitted to grasp a cylinder such as the branch of a tree, it was much less able than the human hand to grasp a sphere. Hepburn [2] has compared the hands of the four anthropoids with that of man, and shown how the development in the latter of the muscles of thenar and hypothenar eminences has modified the position of the creases. In the gibbon the fingers are capable of flexion and adduction to the middle line, but have little tendency to oppose the thumb; the transverse and longitudinal creases are therefore met with. In man opposition of the thumb to the fingers is one of the most prominent characteristics of the hand, and the creases in consequence are oblique.

\section{The Foot.}

The foot (Pl. V. fig. 1, B), from the point of the heel to the end of the middle toe, measures $14 \mathrm{~cm}$. in length, of which two thirds belong to the sole and one third to the toes. The width of the sole, exclusive of the great toe, is $2 \cdot 6 \mathrm{~cm}$. The hallux reaches to the level of the proximal interphalangeal joint of the second toe. Unlike the foot of man, the hallux is not bound up parallel to the other digits, but becomes free just beyond the mid-point of the sole. Behind this point it is marked off from the rest of the foot by a deep crease. The hallux is a much more powerful digit than the pollex. All the toes have a tendency to point outwards, being set at an angle to the plane of the long axis of the sole. In consequence of this angle the four outer digits, on flexion, oppose the great toe. The web of the four outer toes reaches about halfway down the proximal phalanges and prevents any great separation of these digits.

'T'he following are the chief skin-creases found in the sole :-

1. On looking at the sole it is seen to be divided into two unequal parts by a longitudinal crease which starts on the inner side of the heel and, passing forwards, gradually deepens into a cleft which divides the great toe from the rest of the sole. The smaller of these portions carries the hallux, while the larger bears the four outer toes. This dividing crease and cleft are caused by the opposability of the hallux.

2. From the preceding crease near its commencement, another smaller crease passes outwards and forwards in front 
of the heel, and corresponds to a similar crease in the hand of the ape. In the human foot neither of these creases is seen.

3. A well-marked crease runs transversely across the sole, even on to the hallux just behind the point where that digit becomes free from the rest of the foot.

4. A still deeper crease runs transversely across the sole just behind the metacarpo-phalangeal articulations. This marks the place at which the long axes of the sole and digits meet at an obtuse angle.

5. At the root of the four other toes there is a deep double crease which slopes from the margins of the foot forward to the middle digit. Creases 3,4 , and 5 are caused by the folding of the tissues on flexion of the toes into the sole. Hepburn [2] figures a crease in the foot of the gibbon running longitudinally, and ascribes its presence to the contractions of the adductor (contrahentes) layer of muscles. In my specimen this crease was absent, and it is interesting to note that the adductor muscles of the four outer toes were also wanting.

The creases and the finer lines on the toes correspond to, but are not so well marked as, those found on the fingers. The finer lines on the sole start from the heel and pass in wide curves to the margin of the foot: those on the onter side to the outer margin; those in the centre forward with a slight general inclination inward; and those on the inner side forward and inward to the cleft between the sole and great toe. This same arrangement is reprodiced on a smaller scale on the skin of the ball of the great toe.

The description of the finger-nails applies equally to the toe-nails. The ungual phalanges of the toes were, if anything, a trifle more bulbous than those of the fingers.

From my account it is clear that there is much less resemblance between a man's and a gibbon's foot than there is between their hands. In fact, of the hand and foot of the gibbon, it is the latter which more closely resembles the human hand. The central digit of the ape's foot and hand corresponds to the central digit of the human hand, namely the third, while the central digit of the human foot is the second. The marked difference between the hand and foot of man is due to specialization. Man uses his hand, said Goodsir, "as an instrument for acting on matter, in the terms of his human faculty of thinking in space "; while his foot is an organ merely of support and progression. Commonly all other functions are precluded, for the foot is enclosed in a boot. But among peoples, such as the natives of India, 
where custom does not confine the feet in coverings, the human foot retains a certain amount of its prehensile power. In the ape the foot is far superior to the hand as a prehensile organ, for not only is the hallux better developed than the pollex, but it has much greater power to oppose the other digits. Grasping and progression in aninals of arboreal habits are to some extent synonymous. In the human foot the hallux is so bound up with the rest of the foot that it is practically incapable of any independent action.

\section{References.}

[r] 'Anatomical Memoirs of John Goodsir.' Vol. I. Edited by W. Turner.

[2] 'Journal of Anatomy and Physiology', 1893.

\section{EXPLANATION OF PLATE V.}

Fig. 1. A, hand, B, foot of Hylobates agilis, to show the arrangement of the creases. Owing to the hook-like position of the hand, the finger-tips are out of focus.

Fig. 2. Skin from the palmar aspect of the fingers, to show the chevronlike arrangenent of the fine lines.

XXVI.-On Neotropical Mammals of the Genera Callicebus, Reithrodontomys, Ctenomys, Dasypus, and Marmosa. By OldField Thomas.

\section{Callicebus pallescens, sp. $\mathrm{n}$.}

Allied to C. donacophilus, d'Orb., with which it shares the greyish-white hands, feet, and tail, but the head and body are almost of the same pale colour, so that the whole animal is one of the palest and most uniformly coloured species of the group.

Size very small. Fur thick and soft; the longer hairs of back about 60 , the shorter $35 \mathrm{~mm}$. in length. General colour of body pale greyish, suffused with pinkish buff; the long hairs indistinctly ringed with whitish and black, the underfur pinkish buff for its terminal half, its basal half dark brown. Under surface and inner side of limbs rufous, rather paler than in C. donacophilus. Head rather yellower than back, owing to the hairs being tipped with yellow, but the difference is not conspicuons. Muzzle and lips whitish. Hands and feet greyish white. Tail also greyish white, but the hairs inconspicuously ringed with blackish.

Ann. \& Mag. N. Hist. Ser. 7. Vol. xx. 